\title{
Relationship between Anthropometry and Motor Abilities at Pre-School Age
}

\author{
Daniela De Toia ${ }^{\mathrm{a}}$ Daniel Klein ${ }^{\mathrm{a}}$ Sarah Weber ${ }^{\mathrm{a}}$ Nicolas Wessely ${ }^{\mathrm{a}}$ Benjamin Koch ${ }^{\mathrm{a}}$ \\ Walter Tokarski $^{b} \quad$ Sigrid Dordel $^{c}$ Heiko Strüder ${ }^{a} \quad$ Christine Graf $^{a}$ \\ a Institute of Movement and Neurosciences, \\ ${ }^{\mathrm{b}}$ Institute of European Sport Development and Leisure Studies, \\ ${ }^{c}$ Institute of School Sport and School Development, German Sport University Cologne, Germany
}

\section{Key Words}

Kindergarten · Pre-school children - Obesity . Overweight · Motor abilities

\section{Summary}

Objective: Little is known to date about the relationship between poor motor abilities and overweight or obese pre-school children. Thus, this study examined the association between motor abilities and weight status in 1,228 kindergarten children (45.8\% female). Method: Anthropometric data were assessed; age $4.7 \pm 1.0$ years; height $108.6 \pm 8.0 \mathrm{~cm}$; weight $19.1 \pm 3.6 \mathrm{~kg}$; BMI $16.1 \pm$ $1.5 \mathrm{~kg} / \mathrm{m}^{2}$. The modified Karlsruher Motor Ability Screening Test was carried out to determine the motor abilities of speed strength, muscular endurance, coordination, flexibility, and speed. Results: Based on the German $\mathrm{BMI}$ reference values, $3.5 \%$ of the children were obese, $9.6 \%$ overweight, $83.4 \%$ normal weight, and $3.5 \%$ underweight. During various test tasks, below-average motor abilities were discovered in 44.0-47.3\%. In all age groups, overweight and obese children did not differ from their normal and underweight counterparts; except for underweight children which fared worse in flexibility. Conclusion: In contrast to former studies with first graders, overweight or obese pre-school children did not possess worse motor abilities than normal weight children. However, the high number of overweight children and motor deficits suggests that preventive measures should start at this early age.

\section{Introduction}

Excess weight already constitutes an increasing problem in children of pre-school age [1-4]. National surveys of children and adolescents in Germany (KIGGS) have shown that $8.7 \%$ of children aged 3-18 years are overweight and 6.3\% are obese. The proportion of overweight children of pre-school age is $6.2 \%$ and the proportion of obese children in this group is $2.9 \%$ [5]. A high occurrence of overweight children and adolescents has also been noted in other countries based on different national and international classification systems, e.g. $25 \%$ and $11 \%$ in the USA [6].

Besides a genetic predisposition and low socioeconomic status, overweight and obesity are the consequence of an imbalanced energy intake and consumption. A lack of movement experiences caused by physical inactivity may also lead to poor motor abilities and aggravated avoidance behaviour. According to Reilly et al. [7], British pre-school children are only physically active for a period of 20-25 min per day. The consequences regarding motor abilities are measurable concerning both coordination and energy-determined abilities. Bös [4] established that children's and adolescents' motor abilities had deteriorated by an average exceeding $10 \%$ during the period between 1975 and 2000. Gaschler [8] described a prevalence of motor ability abnormalities in pre-school children that ranged between 8 and 24\%. Graf et al. [9] confirmed this relationship for first grade pupils and older populations. Conversely, an active lifestyle (participation in sports clubs and additional regular activities) correlated with better coordination and endurance performance [9]. This relationship between anthropometry and motor abilities is little-known at pre-school age. To date, only Bappert et al. [10] have been able to prove a link between children being overweight and worse performances by obese children in selected tasks defined in the Karlsruher Motor Ability Screening Test (KMS).

\section{KARGER}

Fax +497614520714

Information@Karger.de

www.karger.com (c) 2009 S. Karger GmbH, Freiburg

Accessible online at:

www.karger.com/ofa 
Table 1. Anthropometrical data of the children indicating mean values, standard deviation, and ranges

\begin{tabular}{lrllr}
\hline & \multicolumn{1}{l}{ Girls } & \multicolumn{1}{l}{ Boys } & p-value* & \multicolumn{1}{l}{ Total } \\
\hline Age, years & $4.7 \pm 1.0(\mathrm{n}=563)$ & $4.7 \pm 0.9(\mathrm{n}=665)$ & \multicolumn{1}{l}{0.15} & $4.7 \pm 1.0(\mathrm{n}=1,228)$ \\
Height, $\mathrm{cm}$ & $107.8 \pm 8.1(\mathrm{n}=554)$ & $109.2 \pm 7.8(\mathrm{n}=662)$ & 0.002 & $108.6 \pm 8.0(\mathrm{n}=1,216)$ \\
Weight, $\mathrm{kg}$ & $18.7 \pm 3.7(\mathrm{n}=563)$ & $19.3 \pm 3.5(\mathrm{n}=665)$ & 0.005 & $19.1 \pm 3.6(\mathrm{n}=1,228)$ \\
BMI, $\mathrm{kg} / \mathrm{m}^{2}$ & $16.0 \pm 1.6(\mathrm{n}=554)$ & $16.1 \pm 1.5(\mathrm{n}=662)$ & 0.281 & $16.1 \pm 1.5(\mathrm{n}=1,216)$ \\
\hline
\end{tabular}

*Independent t-test.
Without a doubt, physical activity promotes children's physical, social, and emotional development. Therefore, besides its role in the aetiology of overweight, the early detection of motor deficits followed by preventive measures may play an important role in the setting of the kindergarten. That is why the initial survey carried out with the Kindergarten Mobil (KiMo) project examined the prevalence of motor deficits and potential relationships between weight status and motor abilities in children of pre-school age.

\section{Participants and Methods}

\section{Design and Group}

Twenty-seven kindergartens in Cologne were examined. The study took place between December 2006 and April 2008 with the approval of the Ethics Commission at the German Sport University Cologne and the survey being conditional on the parents providing their written consent.

\section{Assessment of Anthropometric Data}

The current age was determined from the date of birth and the date of the survey. The weight and height of the children were measured using Seca 761 scales and a Seca 225 calibrated rule. The children were measured and weighed in light clothing without shoes. The BMI was calculated as the body weight in kilograms divided by size in metres squared. Obesity was defined at BMI $>97$ th percentile, the children being overweight at BMI $>90$ th percentile but $<97$ th percentile, normal weight at BMI $\geq 10$ th percentile but $<90$ th percentile, and underweight as BMI $<10$ th percentile. The collected values were categorised in accordance with national reference data $[11,12]$.

The anthropometric data for 1,228 children was collected $(45.8 \%$ female). The average age was $4.7 \pm 1.0$ years, the mean body height was $108.6 \pm 8.0 \mathrm{~cm}$, the average body weight was $19.1 \pm 3.6 \mathrm{~kg}$, and the BMI was $16.1 \pm 1.5 \mathrm{~kg} / \mathrm{m}^{2}$ (table 1). Girls were smaller and lighter than boys (each $\mathrm{p}<0.05$ ); no differences were found concerning age and BMI (table 1).

\section{Motor Ability Tests}

The assessment of motor abilities in pre-school children is handicapped by a lack of validated test tools. Therefore, the KMS 3-6 with its test items of standing long jump, stand and reach, lateral jumping, and one leg stand on a bar with a width of $3 \mathrm{~cm}$ was used in this survey for reasons of practicability in kindergartens and test economy. The reliability of all test items is indicated as $r=0.8-0.9$ [13]. The results were classified using the age- and sex-specific standards set out by Bös et al. [13] in five categories from very good to poor; 'sufficient' and 'poor' were regarded as below average for motor abilities. In addition, the shuttle run test in accordance with Krombholz [14] was also carried out as were the tests one leg stand on a bar with a width of $4.5 \mathrm{~cm}$ and the sit and reach test [15]. No classifications for pre-school age were available here.
The children undertook the fitness tests in the morning at the kindergartens' movement rooms under the supervision of a test leader assigned to them. All stations were explained and demonstrated by the test leader before the child was asked to do the tests. The tests were carried out with sports shoes. Only the stand and reach and sit and reach tests were carried out in socks.

- Standing long jump: This test examined speed strength in the lower extremities. The children were asked to jump from a line with both legs forwards as far as possible and land on both legs without falling over. The better of 2 attempts was used in the study.

- Lateral jumping: Coordination under time pressure and muscular endurance was determined in this test. The children were asked to stand on a wooden board $(60 \times 100 \times 0.8 \mathrm{~cm})$ and to jump sideways back and forth across a central bar with both legs as quickly as possible. Jumps that landed on the central line were not counted. The attempts from $2 \times$ $15 \mathrm{~s}$ were counted.

- One leg stand: Static balance was tested on a $3 \mathrm{~cm}$ (KMS) and on a 4.5 $\mathrm{cm}$ wide wooden bar. The children were asked to stand as still as possible on one leg for $1 \mathrm{~min}$. The test leaders recorded floor contact with the other leg. The test was discontinued when 30 floor contacts were exceeded.

- Stand and reach: The flexibility of the hip joint, the lumbar spine area, and the capacity to stretch in the ischiocrural muscles was examined in this test. A wooden box $(15 \times 44.5 \times 32 \mathrm{~cm})$ with a centimetre scale was used in this test. The child was asked to stand with stretched knees on the box and move both hands simultaneously through a hip flexion downwards as far as possible on the scale. Zero point was set at the level of the soles of the feet; values below were noted as positive centimetres and values above as negative.

- Sit and reach: This test examined the same ability as the stand and reach test. The child was asked to sit down with stretched knees and then push a box $(31 \times 32 \times 30 \mathrm{~cm})$ on a centimetre scale forwards.

- Shuttle run: Speed and coordination were determined in this test. 2 squares sized $30 \times 30 \mathrm{~cm}$ were marked on the floor at a distance of four metres from each other. 2 wooden blocks sized $3.8 \times 3.8 \times 3.8 \mathrm{~cm}$ were placed in 1 square. The child was asked to start in the square without wooden blocks and then carry the wooden blocks separately into the empty square, thus covering the distance 4 times. The time was taken with a stop watch.

\section{Statistics}

The collected data was statistically processed using the SPSS 16.0 program (SPSS Inc.; Chicago, IL, USA). The descriptive statistics calculated mean arithmetic values, standard deviations (SD), and maximum $(\max )$ and minimum $(\mathrm{min})$ values. One-factorial analyses of variances (ANOVA) were carried out for the comparison of the independent variables with more than two characteristics; e.g. test results from the different BMI classifications. The relationships between two categorical variables were tested indirectly using the chi-square test. An error probability value of $p \leq 0.05$ was regarded as significant in the interpretation of the results. 
Table 2. Results of the fitness test indicating $\mathrm{N}$, min, max, mean values, and $\mathrm{SD}$; p-values refer to sex differences

\begin{tabular}{|c|c|c|c|c|c|c|}
\hline & $\mathrm{N}$ & Min & Max & Mean & $\mathrm{SD}$ & $\mathrm{p}$-values ${ }^{\mathrm{a}}$ \\
\hline \multicolumn{7}{|c|}{ Standing long jump, $\mathrm{cm}$} \\
\hline Total & 1,201 & 3.0 & 130.0 & 69.5 & 25.2 & \multirow{3}{*}{$<0.001$} \\
\hline Boys & 652 & 3.0 & 130.0 & 72.2 & 26.1 & \\
\hline Girls & 549 & 15.0 & 121.0 & 66.3 & 23.7 & \\
\hline \multicolumn{7}{|c|}{ Stand and reach, $\mathrm{cm}$} \\
\hline Total & 1,174 & -20.0 & 18.0 & -1.0 & 6.5 & \multirow{3}{*}{$<0.001$} \\
\hline Boys & 639 & -20.0 & 16.0 & -2.0 & 6.6 & \\
\hline Girls & 535 & -20.0 & 18.0 & 0.2 & 6.3 & \\
\hline \multicolumn{7}{|c|}{ Sit and reach, $\mathrm{cm}$} \\
\hline Total & 1,053 & -20.0 & 16.0 & 2.5 & 5.0 & \multirow{3}{*}{$<0.001$} \\
\hline Boys & 577 & -20.0 & 16.0 & 1.7 & 5.2 & \\
\hline Girls & 476 & -12.0 & 16.0 & 3.4 & 4.7 & \\
\hline \multicolumn{7}{|c|}{ Lateral jumping, jumps } \\
\hline Total & 1,188 & 0.0 & 62.0 & 19.3 & 9.5 & \multirow{3}{*}{0.537} \\
\hline Boys & 650 & 0.0 & 62.0 & 19.4 & 9.6 & \\
\hline Girls & 538 & 0.0 & 54.0 & 19.1 & 9.4 & \\
\hline \multicolumn{7}{|c|}{ One leg stand $4.5 \mathrm{~cm}$, floor contacts } \\
\hline Total & 998 & 0.0 & 30.0 & 14.6 & 7.5 & \multirow{3}{*}{0.001} \\
\hline Boys & 530 & 0.0 & 30.0 & 15.3 & 7.4 & \\
\hline Girls & 468 & 0.0 & 30.0 & 13.7 & 7.6 & \\
\hline \multicolumn{7}{|c|}{ One leg stand $3.0 \mathrm{~cm}$, floor contacts } \\
\hline Total & 829 & 0.0 & 30.0 & 20.2 & 6.7 & \multirow{3}{*}{0.003} \\
\hline Boys & 420 & 0.0 & 30.0 & 20.9 & 6.3 & \\
\hline Girls & 409 & 1.0 & 30.0 & 19.5 & 7.0 & \\
\hline \multicolumn{7}{|c|}{ Shuttle run, $s$} \\
\hline Total & 1,213 & 7.4 & 36.0 & 11.7 & 3.1 & \multirow{3}{*}{$<0.001$} \\
\hline Boys & 662 & 7.4 & 28.0 & 11.4 & 2.9 & \\
\hline Girls & 551 & 7.5 & 36.0 & 12.1 & 3.4 & \\
\hline
\end{tabular}

\section{Results}

\section{Anthropometric Data}

Table 1 shows the baseline data both in the entire group and gender-specific. Based on the German BMI reference values as specified by Kromeyer-Hauschild et al. [11], 3.5\% of children were obese, $9.6 \%$ overweight, $83.3 \%$ were of normal weight, and $3.5 \%$ were underweight.

\section{Sex-Specific Consideration}

By sex, 3.0\% of boys were obese, 10.1\% overweight, $83.4 \%$ normal weight, and $3.5 \%$ underweight; $4.2 \%$ of girls were obese, $9.0 \%$ overweight, $83.2 \%$ normal weight, and $3.6 \%$ underweight. These differences between boys and girls were significant $(\mathrm{p}<0.001)$.

\section{Motor Ability Tests}

The results of the motor ability tests are shown in table 2 . Below-average motor abilities were found in $44.0-47.3 \%$ of all children; accurately defined: $44.0 \%$ for the standing long jump, $45.5 \%$ in the stand and reach test, $45.9 \%$ in the lateral jumping, and $47.3 \%$ in the one leg stand test $(3 \mathrm{~cm}$ rail).

Relationship between Motor Abilities and BMI Classifications Except in the stand and reach and sit and reach tests, no differences were found between motor abilities and BMI classifications (table 3 ). In the stand and reach test, the underweight children were not as flexible as those with normal weight ( $\mathrm{p}=$ $0.013)$, the obese $(p=0.001)$, and the overweight $(p=0.006)$. The underweight children were not as flexible as the overweight ones $(p=0.024)$ in the sit and reach test. No differences were found (data not shown) when the children were divided into age groups (3-3.9 years, 4-4.9 years, 5-5.9 years, and $>6$ years).

Sex-Specific Consideration between Motor Abilities and BMI Classifications

Differences in the stand and reach test and sit and reach test were only apparent in the sex-specific consideration for boys 
Table 3. Results of the fitness test according to BMI classification indicating $\mathrm{N}$, min, max, mean values, and SD; p-values refer to sex differences

\begin{tabular}{|c|c|c|c|c|}
\hline & $\mathrm{N}$ & Mean & $\mathrm{SD}$ & p-values ${ }^{\mathrm{a}}$ \\
\hline \multicolumn{5}{|c|}{ Standing long jump, cm } \\
\hline Obesity & 42 & 68.2 & 23.7 & 0.835 \\
\hline Overweight & 113 & 67.6 & 22.5 & \\
\hline Normal weight & 991 & 69.7 & 25.7 & \\
\hline Underweight & 42 & 70.5 & 21.6 & \\
\hline \multicolumn{5}{|c|}{ Stand and reach, $\mathrm{cm}$} \\
\hline Obesity & 41 & 1.2 & 6.1 & 0.001 \\
\hline Overweight & 113 & -0.3 & 6.3 & \\
\hline Normal weight & 968 & -1.1 & 6.5 & \\
\hline Underweight & 41 & -4.2 & 7.6 & \\
\hline \multicolumn{5}{|l|}{ Sit and reach, $\mathrm{cm}$} \\
\hline Obesity & 41 & 3.2 & 5.6 & 0.026 \\
\hline Overweight & 100 & 3.0 & 4.7 & \\
\hline Normal weight & 871 & 2.4 & 5.0 & \\
\hline Underweight & 35 & 0.2 & 6.2 & \\
\hline \multicolumn{5}{|c|}{ Lateral jumping, jumps } \\
\hline Obesity & 42 & 19.1 & 8.8 & 0.263 \\
\hline Overweight & 114 & 17.6 & 8.2 & \\
\hline Normal weight & 979 & 19.5 & 9.7 & \\
\hline Underweight & 42 & 19.1 & 8.1 & \\
\hline \multicolumn{5}{|c|}{ One leg stand $4.5 \mathrm{~cm}$, floor contacts } \\
\hline Obesity & 33 & 16.7 & 7.7 & 0.071 \\
\hline Overweight & 97 & 15.9 & 8.0 & \\
\hline Normal weight & 823 & 14.3 & 7.4 & \\
\hline Underweight & 36 & 13.8 & 7.7 & \\
\hline \multicolumn{5}{|c|}{ One leg stand $3.0 \mathrm{~cm}$, floor contacts } \\
\hline Obesity & 24 & 20.8 & 6.4 & 0.780 \\
\hline Overweight & 82 & 20.8 & 6.5 & \\
\hline Normal weight & 682 & 20.1 & 6.8 & \\
\hline Underweight & 34 & 20.2 & 6.0 & \\
\hline \multicolumn{5}{|l|}{ Shuttle run, s } \\
\hline Obesity & 42 & 11.2 & 2.1 & 0.621 \\
\hline Overweight & 114 & 11.6 & 2.9 & \\
\hline Normal weight & 1,005 & 11.7 & 3.2 & \\
\hline Underweight & 41 & 11.4 & 2.3 & \\
\hline
\end{tabular}

${ }^{\mathrm{a} O n e-f a c t o r i a l ~ v a r i a n c e ~ a n a l y s i s ~(A N O V A) . ~}$

(stand and reach: $\mathrm{p}=0.001$; sit and reach: $\mathrm{p}=0.017$ ). Underweight boys were not as flexible in the stand and reach test as obese boys $(\mathrm{p}=0.013)$, overweight boys $(\mathrm{p}=0.001)$, and boys with normal weight $(\mathrm{p}=0.001)$. Underweight boys were not as flexible in the sit and reach test as overweight boys ( $p$ $=0.014)$ and boys with normal weight $(\mathrm{p}=0.035)$. Overall, there were no differences in lateral jumping; the distinction between sexes, however, showed a difference in girls ( $\mathrm{p}=$ $0.004)$. The overweight girls came out worse than obese girls $(\mathrm{p}=0.019)$ and girls with normal weight $(\mathrm{p}=0.007)$ (data not shown).

\section{Discussion}

A higher occurrence of overweight and obese children was discovered in this study than had previously been recorded in existing German data (13.1\% compared to $9.1 \%$ ) [5]. This may be due to regional differences as Cologne is a mainly urban environment. Overweight and obesity is caused by physical inactivity, among high energy intake, low socioeconomic status, and genetic determinants $[16,17]$. Physical inactivity can also result in motor deficits. In this study, $44.0-47.3 \%$ of all children showed below-average motor abilities in the various tests [9, 13].

In elder populations (first through tenth graders), overweight and obese children performed worse results in all main motor abilities (endurance, strength, coordination, and flexibility) [13]. In contrast to those previous surveys [9, 13], this study did not discover any link between motor abilities and BMI classifications in pre-school children. Underweight boys were only less flexible in the stand and reach and sit and reach tests.

To date, only Bappert et al. [10] have been able to prove a link between pre-school children being overweight and worse performances by obese children in selected tasks defined in the KMS. Bappert et al. [10] and Bös et al. [13] surveyed 1,288 kindergarten children in Karlsruhe within the scope of the 'Children's Health' model project/standardization of KMS 3-6. Here, children with normal weight achieved significantly better results in the standing long jump and in lateral jumping than overweight children. Overweight children, in contrast, showed significantly better flexibility in the stand and reach test. Possibly, this is due to the fact that the added body weight creates an advantage in the test for assessing flexibility because it works with gravity and thus passively increases the ability to stretch. This study only showed a significant difference when underweight boys were compared with other weight classifications. The differences were revealed in the stand and reach and sit and reach tests. Therefore, it cannot be explained due to gravity.

Butterfield et al. [18] examined the relationship between $\mathrm{BMI}$ and the qualitative execution of fundamental movement abilities (e.g. running, galloping, jumping) and the results from various fitness tasks (hand strength, step test, sit and reach, situps) in 65 children aged between 5 and 8 years. Comparable to our results, the BMI did not affect the test results. Only the results from the sit and reach test were comparable with the results from this study. The authors conclude that the development of motor abilities at this age possibly depends on other factors, e.g. participation in available activities. In the fitness tasks, the BMI correlated positively with the strength of hand grip and negatively with the number of sit-ups achieved in 1 min. The pulse rate in the step test and flexibility in the sit and reach test revealed no link to BMI.

Other studies in kindergartens that focused both on anthropometrical as well as motor ability parameters also found no relationship between BMI and motor ability performances $[14,19]$. 
A corresponding relationship may possibly only become apparent with increasing age. This survey found no difference between age but Graf et al. [9, 20] showed considerably worse performances by overweight and obese first grade pupils. Within the scope of the CHILT project, they examined 668 first grade pupils using body coordination tests for children and a 6-min run. Huber [21], who examined 1,334 primary school children within the 'Kids Aktiv' project, reached the same conclusion using the same tests. Dordel and Kleine [22] studied 360 fourth graders using the 6-min run, the 20-metre sprint, running over hurdles, and one leg stand. In nearly all tasks, overweight and obese children performed worse test results. No differences were found in those tasks which demanded coordination, e.g. throwing at targets and rod-grabbing, and which were not affected by the extra weight. Overweight children achieved the best results in medicine ball throwing, an activity which permits body weight to be employed with positive effect [22]. An important limitation of this research is its cross-sectional character, which renders causal interferences between weight status and motor abilities uncertain [9]. Therefore, longitudinal studies are needed to clarify the postulated relationship.
In summary, the results of this survey, however, indicate a high number of children with overweight, obesity, and, apart from that, a high number of motor deficits. The findings underline the requirement of preventive measurements to avoid both overweight and motor deficits. The lacking link between overweight/obesity and motor deficits may offer a chance that an early start may break through the vicious circle of physical inactivity, followed by poor motor abilities, with frustration and further avoidance causing overweight in later life.

\section{Acknowledgement}

We gratefully appreciate the AOK Rheinland/Hamburg (Cologne Office, Mrs. Fischel), the Förderverein Herzzentrum Köln (Mr. Helmes), the Stadtsportbund Köln (Mr. Kilzer), our students, the educators, parents, and kindergarten children for all their support. We would also like to thank Christiane Klose for critically reviewing the manuscript.

\section{Disclosure}

There is no conflict of interest to declare.

\section{References}

1 Ogden CL, Troiano RP, Briefel RR, Kuczmarski RJ, Flegal KM, Johnson CL: Prevalence of overweight among preschool children in the United States, 1971 through 1994. Pediatrics 1997;99:E1-7.

2 Keller E, Gausche R, Hoepffner W, Burmeister J, Meigen C, Kiess W, Keller A: System 'CrescNet': Erkennung von Störungen des Wachstums und der Gewichtsentwicklung sowie Gewinnung aktueller Entwicklungsdaten. Pädiatrische Praxis 2004;65:569-579.

-3 Kim J, Peterson KE, Scanlon KS, Fitzmaurice GM, Must A, Oken E, Rifas Shiman SL, Rich-Edwards JW, Gillmann MW: Trends in overweight from 1980 through 2001 among preschool-aged children enrolled in a health maintenance organization. Obesity 2006;14:1107-1112.

4 Bös K: Motorische Leistungsfähigkeit von Kindern und Jugendlichen; in Schmidt W, Hartmann-Tews I, Brettschneider WD (eds): Erster Deutscher Kinder- und Jugendsportbericht. Schorndorf, Hofmann, 2003, pp 85-107.

5 Kurth BM, Schaffrath Rosario A: Die Verbreitung von Übergewicht und Adipositas bei Kindern und Jugendlichen. Ergebnisse des bundesweiten Kinder- und Jugendgesundheitssurveys (KiGGS) Bundesgesundheitsblatt 2007;50:737-743.

$\checkmark 6$ Dehghan M, Akhtar-Danesh N, Merchant AT: Childhood obesity, prevalence and prevention. Nutr J 2005;4:24.

7 Reilly JJ, Jackson DM, Montgomery C, Kelly LA, Slater C, Grant S, Paton JY: Total energy expenditure and physical activity in young Scottish children: mixed longitudinal study. Lancet 2004;363: 211-212.
8 Gaschler P: Motorische Entwicklung und Leistungsfähigkeit von Vorschulkindern in Abhängigkeit von Alter und Geschlecht. Haltung Bewegung 1998;18:5-18.

9 Graf C, Koch B, Kretschmann-Kandel E, Falkowski G, Christ H, Coburger S, Lehmacher W, Bjarnason-Wehrens B, Platen P, Tokarski W, Predel HG, Dordel S: Correlation between BMI, leisure habits and motor abilities in childhood (CHILT-Project). Int J Obes 2004;28:22-26.

10 Bappert S, Woll A, Bös K: Motorische Leistungsunterschiede bei über- und normalgewichtigen Kindern im Vorschulalter. Haltung Bewegung 2003;23: 35-37.

11 Kromeyer-Hauschild K, Wabitsch M, Kunze D, Geller F, Geiß HC, Hesse V, von Hippel A, Jaeger U, Johnsen D, Korte W, Menner K, Müller G, Müller JM, Niemann-Pilatus A, Remer T, Schaefer F, Wittchen HU, Zabransky S, Zellner K, Ziegler A, Hebebrand J: Perzentile für den Body-MassIndex für das Kindes- und Jugendalter unter Heranziehung verschiedener deutscher Stichproben. Monatsschr Kinderheilkd 2001;149:807-818

12 Reinehr T, Wabitsch M: Treatment of obese children and adolescents in Germany. J Pediatr Gastroenterol Nutr 2003;37:208.

13 Bös K, Bappert S, Tittlbach S, Woll A: Karlsruher Motorik-Screening für Kindergartenkinder (KMS 3-6). Sportunterricht 2004;53:79-87.

14 Krombholz H: Bewegungsförderung im Kindergarten - Ergebnisse eines Modellversuchs. Teil 2: Ergebnisse der wissenschaftlichen Begleitforschung. Motorik 2004;27:166-182.
15 Koslow RE: Sit and reach flexibility measures for boys and girls aged three through eight years. Percept Mot Skills 1987;64:1103-1105.

16 Klesges RC, Klesges LM, Eck LH, Shelton ML: A longitudinal analysis of accelerated weight gain in preschool children. Pediatrics 1995;95:126-130.

17 Moore LL, Gao D, Bradlee ML, Cupples LA, Sundarajan-Ramamurti A, Proctor MH, Hood MY, Singer MR, Ellison RC: Does early physical activity predict body fat change throughout childhood? Prev Med 2003:37:10-17.

18 Butterfield SA, Lehnhard RA, Coladarci T: Age, sex, and body mass index in performance of selected locomotor and fitness tasks by children in grades K-2. Percept Mot Skills 2002;94:80-86.

19 Ketelhut K, Mohasseb I, Gericke CA, Scheffler C, Ketelhut RG: Verbesserung der Motorik und des kardiovaskulären Risikos durch Sport im frühen Kindesalter. Dtsch Arztebl 2005;102:1128-1136.

20 Graf C, Koch B, Petrasch R, Dordel S: Übergewicht und motorische Fähigkeiten im frühen Schulalter. Haltung Bewegung 2003;23:38-41.

21 Huber G: Abnormales Gewicht als normale Antwort auf eine abnormale Umwelt. Adipositas und Bewegungskompetenz im Kindesalter. Bewegungstherapie Gesundheitssport 2004;20:223-227.

22 Dordel S, Kleine W: Zur Situation übergewichtiger Kinder in der Schule. Ausgewählte Daten zu motorischer Leistungsfähigkeit und zur Körperwahrnehmung, zur Gesundheit und zum Gesundheitsverhalten. Haltung Bewegung 2003;23:7-25. 